\title{
Website Performance Analysis of the Learner Information System (LIS)-Department of Education
}

\author{
Sura J. Amilbahar and Melecio A. Cordero, Jr.
}

\begin{abstract}
Websites to most organizations are technological innovations that will increase their accessibility to helpful information available in the Internet. While most websites are used for advertising and marketing, there are also dynamic websites that have the capability to accept, process, and store information in order to generate reports - all via online like the Learner Information System (LIS) in the Philippines.

The Department of Education wanted to make the records of the learners always available and accurate and to reduce the system-wide inefficiencies brought about by the traditional method. Hence, the implementation of an online system.

This paper assessed the overall performance of the LIS website using different automated tools: Site Analyzer, SEO Site Checkup, Website Grader, and Lipperhey. Each of these tools have different results and interpretation.
\end{abstract}

Keywords - Information technology, Learner Information System, website, website performance analysis.

\section{INTRODUCTION}

The Department of Education (DepEd) has long been making a lot of improvements in order to facilitate one of the most important aspect of a country. The implementation of Learner Information System (LIS) is one of the initiatives made by the said department in order to centralized learner's information and also to gather data from each school recognized by DepEd for analysis and future developments.

Learner Information System was first implemented in government schools and Community Learning Centres in September 2012 through DepEd Order No. 67, s. of 2011 and 2012. The implementation directed the issuance of Learner Reference Number (LRN), a unique number for learners enrolled in schools. LIS also enabled the centralized "Learner Registry" where basic learner information is captured, stored, and accessed through a secured facility to enhance tracking and decision-making on learners at various levels of DepEd management [1].

The use of systems such as LIS have become essential in any school, be it public or private. Data gathered from both LIS and Basic Education Information System (BEIS) have generated school forms that were usually done manually by the advisers and school heads and produced automated reports on pupil-teacher analysis, pupil-instructional room analysis and pupil-furniture analysis [2]. Enhancements were also deployed yearly in order to further develop the system. Facilities such as

Sura J. Amilbahar and Melecio A. Cordero, Jr., Cebu Institute of Technology University, Philippines data housekeeping, data corrections, quick count and the integration of elementary, junior high school and senior high school in one website gave ease to all teachers throughout the Philippines.

Just like any other website that is used for specific purposes and is aiming to gather data that will help an organization or company, LIS should be monitored, checked and tested for further development. Considering its nature of being available online, it is only right to keep LIS at pace with other websites and online systems and utilizing website analyzers are readily available online could genuinely help in the betterment of LIS not just in delivering data to the DepEd but also in being user-friendly to our dear teachers.

The main purpose of this study was to analyse the overall performance of the Learner Information System (LIS). Free, website analyzer applications were utilized such as Site Analyzer [3], SEO Site Chekup, Website Grader and Lipperhey. Steve Webb, a $\mathrm{PhD}$ in Computer Science from Georgia Technology, listed the following criteria in grading the overall performance of a website [4]. These are design, SEO (Search Engine Optimization)/ Visibility, usability, mobile, server \& security, social media/ local, accessibility, and content.

This study assessed the LIS using the following tools: Site Analyzer, SEO Site Checkup, Website Grader and Lipperhey. The overall performance of the website was based on the scores coming from the criteria aforementioned. If a certain website analyzer does not have specific criteria, then the overall performance shown by the tool was suffice as data. The discussion on this paper assumed that no upgrade or enhancements were made on the website after the testing.

\section{RELATED STUDIES}

\section{A. Learner Information System}

Until 1993, school data are gathered and analyzed manually. This has led to conflicting statistics due to data entry errors, lack of coordination to other offices, delayed passing of forms and reports and had also increased the volume of work and delay time [2].

Since its installation and implementation in 2011, Learner Information System (LIS) has given Department of Education auto-generated number of total public school enrolment based on the actual registration of learners. The LIS is an online facility that the Department uses to manage information with the aim of promoting transparency, informed decision making, and empowerment at different levels of the organization. While 
being a tech-based solution, the LIS involves an inclusive, community-driven process that thrives because of the active engagement and participation of all teachers, principals, planning officers and other DepEd personnel all throughout the Philippines [5].

Currently, minor changes can be seen within LIS. Reasons of a learner's dropping out have increased to further pinpoint and narrow down the common problems of learners. LIS can also give data on the number of promoted students, retained students, transfer-ins and outs, data correction and housekeeping facilities and also the auto-generated forms such as SF5 (promoted students with final average rating) and other DepEd school forms. The implementation of LIS also made clear the hierarchy in the levels of management within the Department from school-based, division level, regional, provincial and national levels [6].

\section{B. Web Analytics and Web Metrics}

Web analytics comes from analyzing the interaction of users and a certain website. Usually used in business operations, web analytics can also be used in analyzing website performance and usability [7]. Websites with good overall performance usually attains "preferential attachment" of its users [8].

On a formal definition, web analytics is a mix of measuring, acquisition, analyzing and reporting of data collected from the Internet to understand and optimize web experience [9]. According to a research on understanding web complexity, there are a couple of metrics in the web that needs to be rediscovered such as structure and evolution (design, site map, interconnecting links between websites and the semantic web), performance and optimization (techniques to diagnose bottlenecks in backend infrastructures, search engine optimization, meta-tagging and keywords), web traffic management (measuring the network impact of social network, characterizing end-user behavior, and server and network efficiency), privacy leakage (which focuses more on the security, web access patterns, and impact on page load times) and accessibility (which also includes mobile counterparts and visibility of the webpage in the Internet) [10].

Web analytics also provides data that can be used to increase efficiency of websites and reduce cost in maintenance and enhancement. Web designers and developers use data coming from web analytics in order to improve website usability which leads to website user satisfaction [9].

There are different methods in which data can be gathered then used for web analysis. Ranking, Search Engine Optimization analysis, referrers and keyword analysis, log files, and page tagging [11]. These methods require programs or code snippets injected to each web page in a website in order for the data to be gathered. The use, however, of online applications readily available is commonly used, especially if the company do not have sufficient budget to cover costs.

\section{RESEARCH METHODOLOGY}

\section{A. Data Collection and Research Instrument}

Firstly, the web metrics to be measured were identified. Aforementioned, the metrics that this study were looking into are design, SEO, usability, mobile, server \& security, social, accessibility and content. Due to differences, not all of the chosen website analyzer have the same set of criteria.

The following website analyzers were used: Site Analyzer, SEO Site Checkup, Website Grader and Lipperhey [4]. Table 1 shows the criteria which are present in each of the chosen analyzer.

TABLE I:

THE CRITERIA IN DIFFERENT WEBSITE ANALYZERS

\begin{tabular}{lcccc}
\hline \hline Criteria/Web Metrics & $\begin{array}{l}\text { Site } \\
\text { Analyzer }\end{array}$ & $\begin{array}{l}\text { SEO Site } \\
\text { Checkup }\end{array}$ & $\begin{array}{l}\text { Website } \\
\text { Grader }\end{array}$ & Lipperhey \\
\hline Design & $/$ & $/$ & & $/$ \\
SEO/Visibility & $/$ & $/$ & $/$ & $/$ \\
Usability/Performance & $/$ & $/$ & $/$ \\
Mobile & $/$ & $/$ & \\
Server \& Security & & $/$ & \\
Social Media/Local & & & \\
Accessibility & & \\
Content & & & \\
Overall Score & & & \\
\hline \hline
\end{tabular}

Since the researchers do not have direct access to the codes of the LIS, then code snippets cannot be injected to any other part of the system. Therefore, the website was tested once in every analyzer since there will be no change in the score unless there are modifications in the codes, content, keywords, or design of the LIS itself.

\section{B. Ethical Considerations}

The log-in account details used in the study shall not be disclosed and an email that contains permission letter was sent to the school head before it was used.

\section{FINDINGS AND DisCUSSION}

The following findings were gathered after the testing of the LIS website:

TABLE II: SCORES OF LIS WEBSITE USING SITE ANALYZER

\begin{tabular}{lc}
\hline \hline \multicolumn{1}{c}{ Criteria } & Score/Grade \\
\hline Overall Score & $\underline{\mathbf{5 0 . 2}}$ \\
$\quad$ (out of 100) & $\mathbf{7 8 . 3}$ \\
Design & $\mathbf{4 7 . 6}$ \\
SEO & $\mathbf{7 0 . 5}$ \\
Performance & $\mathbf{3 6 . 8}$ \\
Accessibility & $\mathbf{1 6 . 5}$ \\
Content & \\
\hline \hline
\end{tabular}

The Site analyzer tool shows that LIS website seems to be lacking in content. However, LIS is used for online registry of learners enrolled in any DepEd recognized school, so, basically, it does not contain any other elements than what is encoded by the LIS coordinator or advisers. The overall score of 50.2 out of 
100 is barely above $50 \%$.

TABLE III:

SCORES OF LIS WEBSITE USING SEO SITE CHECKUP

\begin{tabular}{|c|c|}
\hline Criteria & Score/Grade \\
\hline Overall Score (out of 100) & $\underline{72}$ \\
\hline \multicolumn{2}{|l|}{ Design (Passed/Failed) } \\
\hline Sitemap Test & Failed \\
\hline$<\mathrm{h} 1>$ Headings Status & Failed \\
\hline$<\mathrm{h} 2>$ Headings Status & Passed \\
\hline Inline CSS Test & Passed \\
\hline Deprecated HTML tags & Passed \\
\hline HTML Page Size Test & Passed \\
\hline Flash Test & Passed \\
\hline URL Redirects Checker & Failed \\
\hline \multicolumn{2}{|l|}{$S E O$} \\
\hline Meta Title (Yes/No) & Yes \\
\hline Meta Description (Yes/No) & No \\
\hline Google Search Preview (Yes/No) & Yes \\
\hline Robots.txt Test (Passed/Failed) & Passed \\
\hline Broken Links Test (Passed/Failed) & Passed \\
\hline Flash Test & Passed \\
\hline URL Redirects Checker & Failed \\
\hline SEO Friendly URL Test (Passed/Failed) & Passed \\
\hline JS Error Checker (Passed/Failed) & Passed \\
\hline Mobile (Yes/No) & Yes \\
\hline \multicolumn{2}{|l|}{ Security (Passed/Failed) } \\
\hline Safe Browsing Test & Passed \\
\hline Server Signature Test & Passed \\
\hline Directory Browsing Test & Passed \\
\hline Plaintext Emails Test & Passed \\
\hline Social Media (Yes/No) & No \\
\hline
\end{tabular}

The evaluation using SEO Site Checkup revealed that LIS website got a better score of 72 out of 100. Aside from that, LIS passed all the tests under Security and passed mostly the Design and SEO aspects. It is known that LIS can be accessed through mobile phones which give it advantage and wider accessibility however it is not connected to any Social Media sites which is quite understandable since it contains sensitive data about learners.

TABLE IV:

SCORES OF LIS USING WEBSITE GRADER

\begin{tabular}{cc}
\hline \hline \multicolumn{1}{c}{ Criteria } & Score/Grade \\
\hline Overall Score (out of 100) & $\underline{\mathbf{7 2}}$ \\
Performance (30\%) & 22 \\
Page Size (>3MB) & $110 \mathrm{~KB}$ \\
Page Speed (>3secs) & $4.7 \mathrm{secs}$ \\
Page Requests (>100) & 16 \\
Mobile/Accessibility (30\%) & 30 \\
Responsive (Passed/Failed) & Passed \\
Viewport (Passed/Failed) & Passed \\
SEO (30\%) & 10 \\
Page Titles & Passed \\
Meta Description & Failed \\
Headings & Failed \\
Sitemap & Failed \\
Security (10\%) & 10 \\
\hline \hline
\end{tabular}

Website Grader gave LIS website a score of 72 out of 100 . It scored high in Performance, Mobile Accessibility and Security metrics. This could be a good indicator that the LIS is usable and efficient. Getting a low score in SEO is quite understandable since LIS does not really need to utilize Search Engines.

TABLE V: SCORES OF LIS WEBSITE USING LIPPERHEY

\begin{tabular}{|c|c|c|c|}
\hline \multirow{3}{*}{$\begin{array}{l}\text { Criteria } \\
\begin{array}{l}\text { Overall Score } \\
\text { (out of } 100 \%)\end{array} \\
\end{array}$} & \multicolumn{3}{|c|}{ Score/Grade } \\
\hline & $\underline{\mathbf{3 8 \%}}$ & & \\
\hline & $\begin{array}{l}\text { Very } \\
\text { Good }\end{array}$ & Good & $\begin{array}{c}\text { Needs } \\
\text { Improvement }\end{array}$ \\
\hline \multicolumn{4}{|l|}{ Design } \\
\hline Inline styles & & & I \\
\hline Style Blocks & & / & \\
\hline Images & & / & \\
\hline \multicolumn{4}{|l|}{ SEO } \\
\hline Title & & & l \\
\hline Meta Description & & & l \\
\hline Headings & & & l \\
\hline Subheadings & & & I \\
\hline Mobile & l & & \\
\hline Social Media & & & I \\
\hline Accessibility & & l & \\
\hline \multicolumn{4}{|l|}{ Performance } \\
\hline Encoding & & l & \\
\hline Reverse DNS Lookup & & l & \\
\hline Download Speed & & & l \\
\hline Redirecting Domains & & & I \\
\hline
\end{tabular}

LIS website scored 38 out of 100 using Lipperhey analyzer. LIS website weakness is on the Search Engine Optimization (SEO). SEO is more important to e-commerce website but not to online registry system. Performance, however needs improvement, especially on the download speed. Looking at the total feel and look of LIS, it does not contain heavy images or pages but it does connect to a centralized database server in the DepEd Central Office located in Pasig City, Manila, Philippines.

\section{CONCLUSION AND RECOMMENDATION}

This study made use of the 4 different website analyzers in order to assess the overall performance of Learner Information System (LIS) of the Department of Education.

The findings showed that LIS website is weak in terms of the following web metrics: Search Engine Optimization, Social Media, Performance and Content. However, it has a high score in Design, Mobile, Usability, and Server and Security.

The researchers recommend further assessment on the overall performance since a significant number of teachers complain about the speed of the website. Google Analytics is becoming a trend these days. It only needs to inject code snippets into the web pages of the website and it will be able to fully assess the performance of LIS not just in the aforementioned web metrics 
but in specific key performance indicators as well.

\section{REFERENCES}

[1] DO 33 s. 2013, "DO s2013 033.pdf." Department of Education, 2013.

[2] L. Z. Roces, D. B. Genito, and L. Z. Roces, "Basic Education Information System (BEIS ) by Author's name : Designation : Author's name : Designation: Agency: Address : Telephone: Office of Planning Service Department of Education," 2004.

[3] S. Kaur, K. Kaur, and P. Kaur, "Analysis of Website Usability Evaluation Methods," pp. 1043-1046, 2016.

[4] S. P. Webb, "10 SEO Analysis Tools You Should Be Using.” 2012.

[5] M. A. Llego, "DepED Learner Information System (LIS) User's Guide." Teacher Philippines, 2018.

[6] D.O. 52 s. 2016, "Department of Education D.O. 52, s. 2016," 2016
[7] B. Plaza, "Google Analytics for measuring website performance," Tour. Manag., vol. 32, no. 3, pp. 477-481, 2011 https://doi.org/10.1016/j.tourman.2010.03.015.

[8] B. Goncalves and J. Ramasco, "Human dynamics revealed through Web analytics," 2008.

[9] I. Bekavac and D. G. Praničević, "Web analytics tools and web metrics tools : An overview and comparative analysis 2 . Basic concepts related to web analytics and web metrics," vol. 6, pp. 373-386, 2015.

[10] M. Butkiewicz, "Understanding Website Complexity: Measurements , Metrics , and Implications Categories and Subject Descriptors," 2011. https://doi.org/10.1145/2068816.2068846

[11] D. Booth and B. J. Jansen, "A Review of Methodologies for Analyzing Websites," pp. 141-162, 2009

https://doi.org/10.4018/978-1-59904-974-8.ch008. 